\title{
Rhabdomyolysis secondary to systemic lupus erythematosus
}

\author{
Daniel Nguyen ${ }^{1}$ (1) $\cdot$ Farah Alsaati $^{1} \cdot$ Jena Deitrick ${ }^{1} \cdot$ Kamel Azhar $^{1} \cdot$ Evelyn Sbar $^{1}$
}

Received: 14 February 2018 / Accepted: 27 March 2018 / Published online: 6 April 2018

(c) The Author(s) 2018

\begin{abstract}
Systemic lupus erythematous (SLE) is a systemic auto-immune disorder with a variety of presentations and wide spread organ involvement. We present a case report of a patient with an SLE exacerbation as well as concurrent rhabdomyolysis with massively elevated CPK (304,700 U/L). Though a rarely reported effect of SLE, rhabdomyolysis can be severe and potentially lethal secondary or concurrent to an acute SLE episode. This case report demonstrates the association between SLE and rhabdomyolysis, which is not well described in the current literature.
\end{abstract}

Keywords Systemic lupus erythematous $\cdot$ Rhabdomyolysis $\cdot$ Lupus $\cdot$ Myopathy

\section{Introduction}

Systemic lupus erythematosus (SLE) is an auto-immune disorder defined by the 2012 SLICC (Systemic Lupus International Collaborating Clinics Classification Criteria) criteria as having 4 or more out of 11 ARC (American College of Rheumatology) SLE criteria (with at least 1 clinical and 1 laboratory criteria) or a proven biopsy confirming lupus nephritis with a positive ANA or anti-dsDNA. We present a case report of a patient with evidence of both acute cutaneous and systemic lupus, along with synovitis involving two or more joints, positive ANA, and low complement levels of C3. In addition, this patient presented with severely elevated CPK values combined with myalgias suggestive of rhabdomyolysis. While drugs, infections, and inflammatory disorders have been described as causes of non-exertional rhabdomyolysis, SLE appears to be the main causative agent in this case.
Daniel Nguyen

Daniel.K.Nguyen@ttuhsc.edu

1 Texas Tech University Health Sciences Center Amarillo School of Medicine, 1400 S Coulter St, Amarillo, TX 79106, USA

\section{Case report}

A 36-year-old African-American woman presented to the ER with a 3-day history of vomiting, diarrhea, full-body arthralgias, myalgias, and bilateral TMJ stiffness and tenderness, along with severe persistent headache. She had been seen in urgent care 1 week prior to admission with complaints of fever, nausea, and diarrhea. Her medical history was significant for rheumatoid arthritis that had been in remission for 12 years. She was not currently on any maintenance therapy for this auto-immune disease. On arrival, vitals were recorded as BP of 125/89, HR of $92 \mathrm{bpm}$, RR of $18 / \mathrm{min}$, Temperature of $98.3{ }^{\circ} \mathrm{F}$, and $100 \% \mathrm{SpO}_{2}$ on room air. Physical exam was significant for a malar rash, shown in Fig. 1, as well as a second subcutaneous rash on her arms that was erythematous and nodular seen in Fig. 2. In addition, she had bilateral knee effusions along with weakness and edema of the lower extremities.

Labs obtained in the emergency room showed an elevated creatinine level of $2.85 \mathrm{mg} / \mathrm{dL}(0.5-1.0 \mathrm{mg} / \mathrm{dL})$, AST 1293 U/L (10-40 U/L), ALT 397 U/L (7-56 U/L), elevated phosphorus $8.3 \mathrm{mg} / \mathrm{dL}(2.0-4.5 \mathrm{mg} / \mathrm{dL})$, and a low potassium level of $3.1 \mathrm{mmol} / \mathrm{L}(3.5-5.0 \mathrm{mmol} / \mathrm{L})$. CPK was extremely high at $6270 \mathrm{U} / \mathrm{L}(22-198 \mathrm{U} / \mathrm{L})$ and CRP at $9.244 \mathrm{mg} / \mathrm{L}$ $(<3.0 \mathrm{mg} / \mathrm{L})$. The initial differential diagnosis included dermatomyositis/polymyositis/SLE with rhabdomyolysis. She was admitted to the medical floor and given a $3 \mathrm{~L}$ bolus of normal saline along with IV methylprednisolone.

Despite the initial treatment with fluid and steroids, the patient's creatinine and lab values worsened over the next 


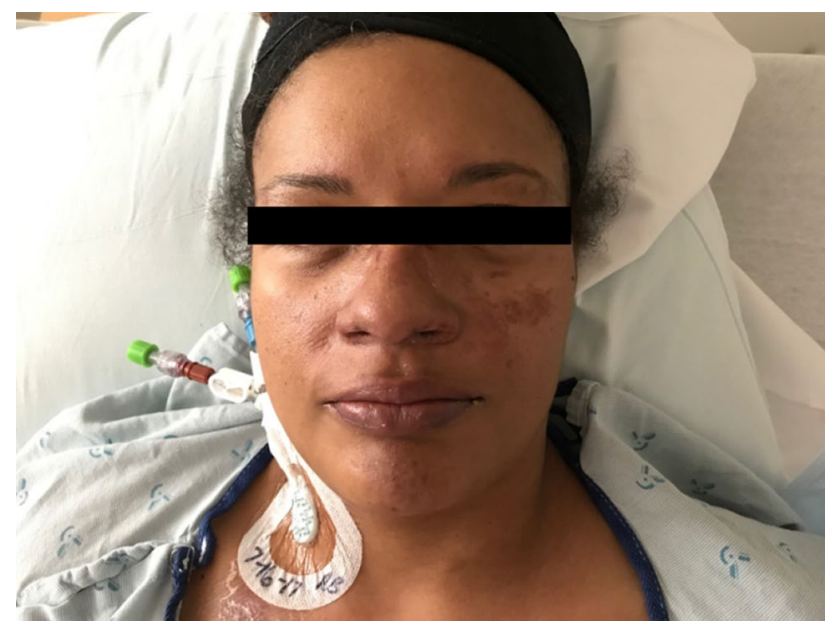

Fig. 1 Malar rash that is purple/red in color that covers the cheeks and nose sparing the rest of the face

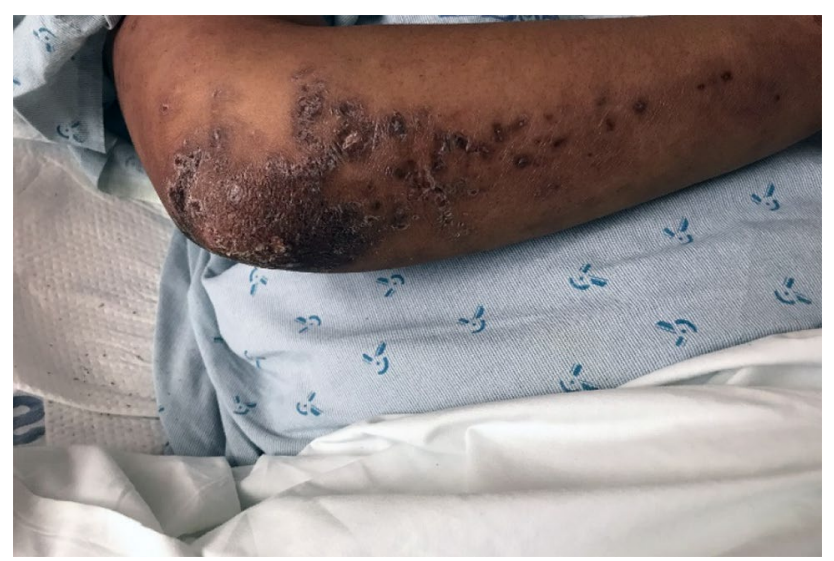

Fig. 2 Subcutaneous rash that is erythematous and nodular

$24 \mathrm{~h}$. Her creatinine rose to $3.59 \mathrm{mg} / \mathrm{dL}$, BUN increased to $70 \mathrm{mg} / \mathrm{dL}$ (7-20 mg/dL), and phosphate jumped to $9.8 \mathrm{mg} /$ dL. In addition, CPK elevated to 207,300 U/L along with an increase in AST and ALT to 1797 and $482 \mathrm{U} / \mathrm{L}$, respectively. Clinically, the patient was also deteriorating; she had been anuric since admission despite fluid resuscitation. The patient was transferred to the ICU, and nephrology and rheumatology were consulted. She was started on a bolus of intravenous corticosteroids to treat rhabdomyolysis secondary to polymyositis after consultants' review. The rheumatologist ordered a panel of auto-immune markers to include CRP, RF, ANA, dsDNA, Ribosomal P, SSA (anti-Ro), SSB (anti-La), snRNP, anti-smith, RNP, centromere B, SCL-70, and Jo- 1 . The results revealed that the CRP was $5.556 \mathrm{mg} / \mathrm{L}$ $(<3.0 \mathrm{mg} / \mathrm{L})$; the RF was $121 \mathrm{IU} / \mathrm{mL}(<15 \mathrm{IU} / \mathrm{mL})$, ANA was greater than $8 \mathrm{IU} / \mathrm{mL}(<8 \mathrm{IU} / \mathrm{mL})$, DsDNA was $1 \mathrm{IU} /$ $\mathrm{mL}(0 \mathrm{IU} / \mathrm{mL}$ ), Ribosomal $\mathrm{P}$ was greater than $8 \mathrm{IU} / \mathrm{mL}$ (IU/ $\mathrm{mL}<8)$, SSA (anti-Ro) was greater than $8 \mathrm{IU} / \mathrm{mL}(<8 \mathrm{IU} /$
$\mathrm{mL}$ ), SSB (anti-La) was less than $0.2 \mathrm{IU} / \mathrm{mL}(<1 \mathrm{IU} / \mathrm{mL})$, snRNP was less than $0.2 \mathrm{IU} / \mathrm{mL}(<1 \mathrm{IU} / \mathrm{mL})$, anti-smith was less than $0.2 \mathrm{IU} / \mathrm{mL}$ ( $<1 \mathrm{IU} / \mathrm{mL}$ ), RNP was $4.4 \mathrm{IU} / \mathrm{mL}$ $(<1 \mathrm{IU} / \mathrm{mL})$, centromere B was less than $0.2 \mathrm{IU} / \mathrm{mL}(<1 \mathrm{IU} /$ $\mathrm{mL})$, SCL-70 was less than $0.2 \mathrm{IU} / \mathrm{mL}(<1 \mathrm{IU} / \mathrm{mL})$, and Jo-1 was less than $0.2 \mathrm{IU} / \mathrm{mL}(<1 \mathrm{IU} / \mathrm{mL})$.

These lab values suggested a probable diagnosis of SLE. Diagnostic criteria for SLE are based on ACR (American College of Rheumatology) guidelines with a sensitivity of $85 \%$ and specificity of $95 \%$ in patients with 4 out of 11 criteria. This patient had arthritis, photosensitivity, renal involvement, blood disorders, elevated ANA, immunologic phenomena with anti-dsDNA, and a malar rash, giving her an ACR SLE score of 7/11, defining her as having SLE. The SELENA-SLEDAI scoring matrix is a way to assess SLE disease activity using 24 different disease descriptors. Scores of six or above on the SLEDAI grid are considered to be consistent with active disease requiring therapy. The patient had a lupus headache, arthritis, myositis, urinary casts, a rash, low complement levels, and leukopenia having a total of 25 points on the SELENA-SLEDAI scoring matrix. This was consistent with a significant degree of active SLE, and need for aggressive medical therapy.

A central line was placed to initiate hemodialysis to alleviate her acute kidney injury. Prompt hemodialysis corrected her electrolytes and improved her creatinine and BUN within $24 \mathrm{~h}$. However, her CPK continue to escalate to $304,700 \mathrm{U} / \mathrm{L}$ and her anuria persisted. The intravenous corticosteroids were tapered and changed to oral preparations to prevent further fluid overload and edema. Hydroxychloroquine was started 1 week after ruling out G6PD deficiency and the risk of iatrogenic hemolysis.

Over the next week, with continued hemodialysis and steroid treatment, her laboratory and clinical picture improved. CPK levels dropped to within normal range, and creatinine and BUN levels remained consistent and improved (though not normalized) with hemodialysis every other day. Due to persistent oliguria, a renal biopsy was ordered to determine if rhabdomyolysis, SLE, or both were to blame. The biopsy showed muddy brown casts with permanent tubular atrophy, interstitial fibrosis, and massive amounts of myoglobin, implicating rhabdomyolysis, as shown in Figs. 3 and 4, as the main culprit of the acute kidney injury.

\section{Diagnosis}

This patient met 7 out of 11 ARC SLE criteria assigning a diagnosis of Systemic Lupus Erythematosus. The malar and subcutaneous rash, arthritis, leukopenia, Lupus headache, myositis, low $\mathrm{C} 3$ levels, and urinary casts confer an SELENA-SLEDAI score of 25 , indicating a significant disease activity, as well. We speculate that her severe acute 


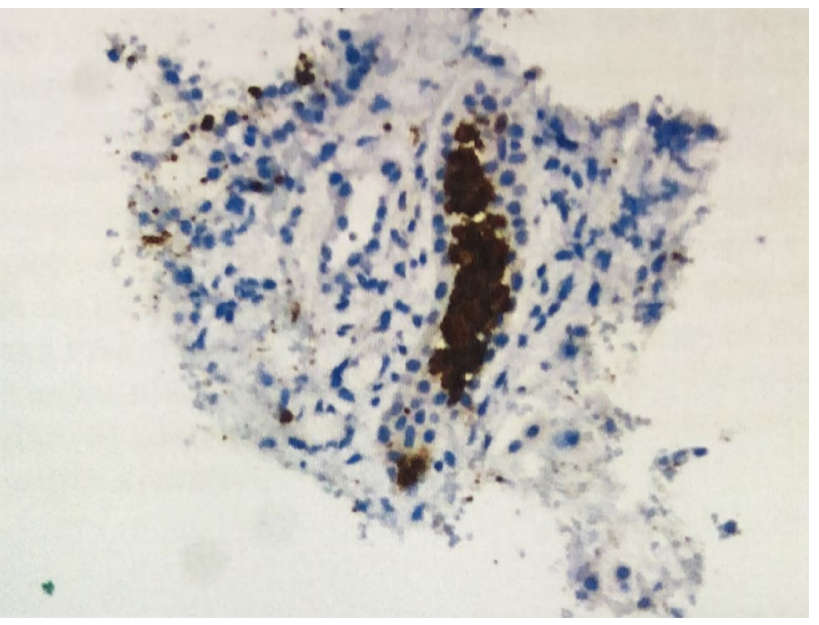

Fig. 3 Kidney biopsy showing positive myoglobin stain in the tubular casts under light microscopy

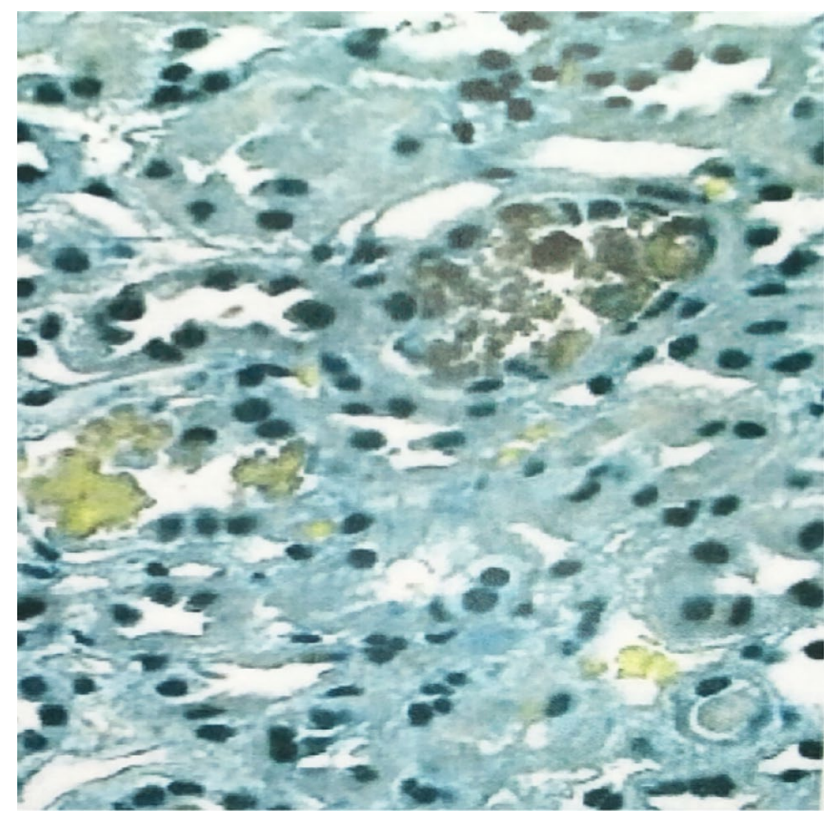

Fig. 4 Kidney biopsy showing brownish casts under light microscopy

gastrointestinal illness triggered a systemic auto-immune reaction and likely indolent SLE, which ultimately led to severe muscle breakdown and resultant acute kidney failure. Over the next few weeks of her inpatient stay, the rash, along with CPK levels, and urine production, responded well to high-dose corticosteroids, hydroxychloroquine, and hemodialysis allowing for renal recovery. Once stabilized and clinically improved, she was able to be discharged. Unfortunately, she has not followed up with nephrology or rheumatology since discharge and the amount of permanent renal damage remains unknown.

\section{Discussion}

There are various auto-immune disorders with overlapping symptoms that are often difficult to distinguish without thorough workup and biopsies. In this case, mixed connective tissue disease cannot be fully ruled out due to the lack of muscle biopsy and further results, but the diagnosis of SLE seems most likely given the symptoms and reported lab values. While the diagnosis of SLE explained some of our patient's symptoms and lab results, it did not fully explain the massively elevated CPK levels. We initially contributed the muscle aches to fatigue and dehydration from vomiting and diarrhea, but the grossly elevated CPK level in the 300,000 s suggested rhabdomyolysis or a necrotizing pathology. Rhabdomyolysis causes are divided into three main categories: traumatic, non-traumatic exertional, and non-traumatic non-exertional. Since our patient did not have a history of trauma or exertion, we will focus on discussing the non-traumatic non-exertional causes.

Non-traumatic non-exertional causes of rhabdomyolysis most commonly include drugs, toxins, and infections. Numerous drugs, both medicinal and illicit, have reportedly caused rhabdomyolysis. These include statins, colchicine, cyclosporine, gemfibrozil, protease inhibitors, creatine, caffeine, heroin, cocaine, amphetamines, methadone, and LSD [1]. Furthermore, toxins such as carbon monoxide, snake and insect venoms, or toxins produced by various mushrooms and fish have been implicated in many cases of rhabdomyolysis [2]. While the mechanism is not yet completely understood, both bacterial and viral infections have also been associated with rhabdomyolysis $[3,4]$. Offending agents include influenza A and B, coxsackievirus, EBV, herpes simplex, parainfluenza, adenovirus, echovirus, HIV, CMV, Mycoplasma pneumoniae, Legionella, Streptococcus, Salmonella, E. Coli, Coxiella, and Staphylococcus aureus [3, 4]. Rhabdomyolysis has also been attributed to endocrine disorders, including diabetes and hypothyroidism, as well as inflammatory diseases, such as polymyositis and dermatomyositis [5, 6].

Due to lack of other contributing factors, we assert that our patient's rhabdomyolysis was potentially a complication of an acute viral or bacterial gastroenteritis and likely undiagnosed indolent SLE. The previous case reports have connected SLE to an inflammatory auto-immune necrotizing myopathy [7]. Others have implicated SLE in the development of rhabdomyolysis in some patients [8]. These reported cases are extremely rare, and their reported CPK values only reached around 50,000, which makes our particular case even more unusual. Regardless, this atypical presentation may suggest a link between SLE and rhabdomyolysis that is not yet well described in the current literature. In addition to this rarely described connection 
between rhabdomyolysis and SLE, others have reported an association between rhabdomyolysis and Sjogren's syndrome [9-11]. However, the current literature does not describe the incidence of rhabdomyolysis secondary to or concurrent with rheumatic diseases.

\section{Conclusion}

SLE spans a wide spectrum of disease presentations with multi-organ involvement which can cause rapid organ failure. Despite establishing the diagnosis of SLE early in the admission, the patient still deteriorated due to complications of her rhabdomyolysis which required a more aggressive treatment plan. As our case and others like it demonstrate, rhabdomyolysis can be seen in patients with SLE, though rarely to this extent $[7,8]$. This case report aims to increase physicians' awareness of rhabdomyolysis as an unusual but possible complication of SLE to aid in more prompt diagnosis and treatment, leading to better patient outcomes.

Funding There was no funding involved with this article.

\section{Compliance with ethical standards}

Conflict of interest The authors Daniel Nguyen, Farah Alsaati, Jena Deitrick, Kamel Azhar, and Evelyn Sbar declare that there is no conflict of interest.

Research involving human participants and/or animals This article does not contain any studies with human participants or animals performed by any of the authors.

Informed consent There is not any informed consent, because this article does not contain any experimentation with human subjects or any identifying elements.

Open Access This article is distributed under the terms of the Creative Commons Attribution 4.0 International License (http://creativeco mmons.org/licenses/by/4.0/), which permits unrestricted use, distribution, and reproduction in any medium, provided you give appropriate credit to the original author(s) and the source, provide a link to the Creative Commons license, and indicate if changes were made.

\section{References}

1. Oshima Y (2011) Characteristics of drug-associated rhabdomyolysis: analysis of 8,610 cases reported to the U.S. Food and Drug Administration. Intern Med (Tokyo, Jpn) 50(8):845-853

2. Huerta-Alardín AL, Varon J, Marik PE (2005) Bench-to-bedside review: rhabdomyolysis - an overview for clinicians. Crit Care (Lond, Engl) 9(2):158-169. https://doi.org/10.1186/cc2978

3. Blanco JR, Zabalza M, Salcedo J, Echeverria L, García A, Vallejo M (2002) Rhabdomyolysis of infectious and noninfectious causes. South Med J 95(5):542-544

4. Pesik NT, Otten EJ (1996) Severe rhabdomyolysis following a viral illness: a case report and review of the literature. J Emerg Med 14(4):425-428

5. Wang LM, Tsai ST, Ho LT, Hu SC, Lee CH (1994) Rhabdomyolysis in diabetic emergencies. Diabetes Res Clin Pract 26(3):209-214

6. Bennett WR, Huston DP (1984) Rhabdomyolysis in thyroid storm. Am J Med 77(4):733-735

7. García-Reynoso MJ, Veramendi-Espinoza LE, Ruiz-Garcia HJ (2014) Paresia ascendente como comienzo de inusual asociación entre miopatía autoinmune necrosante y lupus eritematoso sistémico. Reumatología Clínica 10(3):183-186. https://doi. org/10.1016/j.reuma.2013.03.006

8. de Carvalho JF, da Mota LMH, Bonfa E (2011) Fatal rhabdomyolysis in systemic lupus erythematosus. Rheumatol Int 31(9):12431245. https://doi.org/10.1007/s00296-010-1674-0

9. Cherif E, Ben Hassine L, Kechaou I, Khalfallah N (2013) Hypokalemic rhabdomyolysis: an unusual presentation of Sjogren's syndrome. BMJ Case Rep. https://doi.org/10.1136/bcr-2013-201345

10. Khan UF, Tsu LC, Tan K-B, Huang J, Wong AL (2017) Hypokalaemia in Sjögren's syndrome: the missing piece. Clin Med 17(1):40-42. https://doi.org/10.7861/clinmedicine.17-1-40

11. Prakash EBS, Fernando ME, Sathiyasekaran M, Bhoopathy RM, Jayanth JJ, Samuel J (2006) Primary Sjö-gren's syndrome presenting with distal, renal tubular acidosis and rhabdomyolysis. J Assoc Phys India 54:949-950

Publisher's Note Springer Nature remains neutral with regard to jurisdictional claims in published maps and institutional affiliations. 